\title{
Psychometric Qualities of a Core Set to Ascertain the Functional Profile of Portuguese Elderly Citizens
}

\author{
Maria Goes ${ }^{1}$, Manuel Lopes ${ }^{2}$, Henrique Oliveira ${ }^{3}$, João Marôco ${ }^{4}$, César Fonseca ${ }^{2}$ \\ Margarida Santos ${ }^{5}$, and José Caeiro 6 \\ 1 Escola Superior de Saúde, Instituto Politécnico de Beja, Beja, Portugal \\ 2 Escola Superior de Enfermagem de São João de Deus, Universidade de Évora, Évora, Portugal \\ 3 Instituto de Telecomunicações, IST Torre Norte - Piso 10, Av. Rovisco Pais, Lisbon, Portugal \\ ${ }^{4}$ Instituto Universitário de Ciências Psicológicas, Sociais e da Vida, Lisbon, Portugal \\ 5 Escola Superior de Medicina Tradicional Chinesa, Lisbon, Portugal \\ 6 Instituto de Engenharia de Sistemas e Computadores, INESC-ID, Lisbon, Portugal
}

\begin{abstract}
Objectives: This paper describes the psychometric qualities of a core set composed initially of 31 codes and extracted from International Classification of Functioning, Disability and Health, to ascertain the Functional Profile of Por-tuguese Elderly Citizens, residing in their own home or at a family or friends' home. Methods: Cross-sectional, descriptive study, with a final sample totaled 351 elderlies. Data collected by health professionals in the participants' houses, using the Elderly Nursing Core Set questionnaire. Results: The recommendation of the construct to the EFA was "excellent". Regarding reliability, the construct revealed factorial reliability. In terms of validity, the construct presented factorial validity and convergent validity, although failing regarding discriminant valid-ity. Discussion: Comparing psychometric qualities between the original Elderly Nursing Core Set previously applied to institutionalized citizens in relation to the one presented in this paper (citizens residing in their own home or at a family or friends' home), lead to five latent factors and differences between functional profiles. More than half of the citizens are married and almost half of the sample never went to school, thus revealing an important aspect characterizing a lower literacy level of the citizens involved in this research.

Conclusions: The work based on Core Sets extracted from the International Classification of Functioning, Disability and Health, delineated to assess the nurs-ing care needs and/or the outcomes of nursing interventions of citizens aged 65 years old or older, will be an ongoing process that will lead to the promotion of an Healthy Ageing and functional ability, as stated by World Health Organization.
\end{abstract}

Keywords: Ageing · Elderly residing in the community · Functionality profile assessment . Confirmatory Factor Analysis

\section{Introduction}

Demographic data have been shown that Portugal is one of the European countries presenting one of the highest ageing index (153.2 elderly per 100 young), with this ageing 
phenomena being an ongoing process that will probably last the next fifty or sixty years [1]. This change in the age profile in Portugal (like in other countries of the world) is mainly characterize by two simultaneously processes: (i) the reduction of people with age less than 15 years (a decrease in birth rate and an increase in the emigration of Portuguese young people [2]) along with; (ii) the raise of the average life expectancy that lead to the increase of people with 65 years and more. According to the Statistics Portugal Institute (Instituto Nacional de Estatística - INE) the life expectancy was 80.80 years at birth for the entire Portuguese population, between 2016 and 2018. On the other hand, life expectancy at age 65 attained 19.49 years, also for the entire population, but distributed between man and women as follows: (i) a man aged 65 years could expect to live another 17.58 years; (ii) and woman aged 65 another 20.88 years [3].

However, when introducing "Health" in the context of life expectancy, regarding citizens with aged 65 years, it comes up the concept of "Healthy life years at 65 years". This concept introduces the number of remaining years that a person aged 65 is still expected to live in a healthy condition, i.e., citizens living with the absence of limitations in functioning/disability during a certain period of time. According to the most recent statistics data (year 2017), the healthy life years at 65 for the Portuguese population, by sex, is as follows: (i) 7.9 years for mean; (ii) 6.7 years for mean; whose data puts Portugal almost among with last group of European countries whose citizens that live with less number of Healthy life years [4]. However, despite the aforementioned healthy life years at 65 years, there are citizens who already live with the presence of disabilities after this age, or even earlier.

A recent international report was done, to assess the Portuguese health system in relation to its performance on key challenges and opportunities in the post-financial crisis recovery period, involving the European Observatory on Health Systems and Policies, and the Regional Office for Europe of the World Health Organization (WHO), as well as the Health Portuguese authority (Serviço Nacional de Saúde - SNS). One of the reviewed topics was "Multimorbidity", and the authors of the report state that most adults attending primary health care have more than one chronic condition. Data provided on this report (referred to 2016 and designated by "Burden of Chronic Disease") shows that $41 \%$ users of Portuguese Healthcare System presented multimorbidity (they have equal or more than two chronic diseases (who $53.7 \%$ of them presented four or more chronic diseases), with only $18 \%$ presented one, thus resulting on $41 \%$ of citizens free from any chronic disease [5]. Moreover, multimorbidity may cause serious implications when health personnel need to provide care delivery to citizens in this health condition, which may become a challenge task, because the treatment of one chronic disease will be in the context of other chronic conditions. Regarding age, the same report states that major percentage of citizens with chronic diseases occur between the following age groups:(i) ages between [60-70], 70\% for man and $75 \%$ for women; (ii) and ages between [80-90], 81\% for man and $83 \%$ for women; (iii) followed by a decrease regarding the next age group (ages between [90-150]), more pronounced in man when compared to women, with a medium percentage of $72 \%$ of citizens presenting chronic disease [5].

As citizens are getting older, they become increasingly fragile, presenting functional impairments, multimorbidity (already shown based on the aforementioned data), and a significant prevalence of chronic conditions that easily decompensate them, leading 
to progressive losses, as envisioned by the various biological, psychological and social theories, frequently originating acute health care situations [6-8]. Due to the complexity and heterogeneity of individual aging, the level of functionality may vary distinctly from person to person. Studying the individual aging by integrating a care model in continuity and proximity, allowing the elderlies and family caregivers to monitor and manage their health at home, always under the supervision of health professionals, may result in management of various chronic conditions (multimorbidity) and to provide an appropriated "safety net" before occurring an "health crisis". To achieve this goal, i.e., to promote the quality of life related to the elderly's health, by requalifying their potential and allowing them to live with more independence and autonomy, it is essential: (i) to evaluate his/her their functional capacity in order to identify their disabilities; (ii) identify his/her appropriate self-care behavior that allows diagnosing, planning and assessing the necessary preventive nursing care needs, assuming that the demands of nursing care are high among older adults [9, 10]. Additionally, according to other authors, citizens with multimorbidity have better health outcomes when they benefit from adequate health interventions, structured from previous assessments of their functional level $[8,11]$, allowing us to the get the "big picture" in regard to the presence of disabilities and the overall health state of a person, around several components of his/ her life, such as physical, psychological, social and environmental.

To achieve this goal, i.e., to classify the degree of functioning, the WHO developed the International Classification of Functioning, Disability and Health (ICF), which is the framework for measuring health and disability at both individual and population levels [12]. However, the full ICF taxonomy encompasses an extremely large number of elements. To develop a more manageable means of assessing functioning, several core sets (sets of ICF codes) have being developed [13].

In Portugal, the authors César Fonseca et al. have being done a very important and pioneer work on studding indicators of disability, and more particularly regarding limitations in activities and limitations in the functional capacity, targeting people aged 65 years and older. This important work result on grouping sets of ICF codes (core set), namely the "Elderly Nursing Core Set", aiming to classify the degree of elderlies functioning, which is also capable of even establishing elderly "nursing care needs" [10]. However, as mentioned earlier, their target was people already institutionalized.

Therefore, differing from the work developed by César Fonseca et al., the goal of this research is to study the Psychometric Qualities of the ENCS to ascertain functional profiles of Portuguese elderly citizens living in a rural area at the main Portuguese territory (people residing in their own homes or at a family or friends' home, i.e., in the community, thus not institutionalized). Another aims of the proposed work are as follows:(i) extract (through an Exploratory Factor Analysis- EFA) a set of latent factors that explained the relational structure of items applied to elderly resident citizens; (ii) validate the model extracted from the EFA through a Confirmatory Factor Analysis (CFA), which is not provided in [10]; (iii) a comparison between average functional scores of the entire sample, based on ENCS strategy and the computations of those using the extracted (factor score weights) $f s w$ resulting from CFA (also not provided in [10]). 
Finally, this research will contributes to the lack of population-based studies on socioeconomic, demographic, and health characteristics of the adult population living in rural areas [14].

\section{Methods}

\subsection{Subjects}

This research work involved a sample of citizens with age of 65 and more (elderlies) residing in a rural area namely Baixo Alentejo - BA, located at middle southeast of Portugal main territory that makes border with Spanish region namely Extremadura. 468 participants were selected by stratified random sampling of all 32893 citizens registered in the database of the Health Local Unit of Baixo Alentejo Region (Unidade Local de Saúde do Baixo Alentejo - ULSBA [15]). The sample was stratified by sex (male and female) and by aged group (65-74, 75-84 and 85 and more years old). Data were collected by health professionals in the participants' houses, using the Elderly Nursing Core Set questionnaire developed in [10], between January 2016 and April 2017.

The inclusion criteria rules (only comprising citizens aged 65 or older) were, cumulatively: (i) individuals interested in participating in the study; (ii) residing at the BA region in their own homes or at a family or friends' home; and (iii) those who were able to make decisions, even if sick or hospitalized. The final sample totaled 351 elderlies, those who answered the ENCS questionnaire fully and correctly, and signed the respec-tive informed consent, as well as fulfilled all the stages of the inclusion criteria (response rate of $75 \%$ ). More details about the construction, the main characteristics and the scale used by the codes (items) included in the ENCS can easily be found in [10].

\subsection{Statistical Methods}

The list of 31 ICF codes identified by César Fonseca et al. is shown in Table 1 (extracted from [16]).

Table 1. ICF codes included in ENCS [16].

\begin{tabular}{l|l}
\hline ICF descriptors [17] & ICF codes [18] \\
\hline Body functions & $\mathrm{b} 110, \mathrm{~b} 114, \mathrm{~b} 140, \mathrm{~b} 144, \mathrm{~b} 152, \mathrm{~b} 164, \mathrm{~b} 280, \mathrm{~b} 420, \mathrm{~b} 440, \mathrm{~b} 525$ \\
\hline Body structures & $\mathrm{s} 810$ \\
\hline Activities and participation & $\mathrm{d} 230, \mathrm{~d} 310, \mathrm{~d} 330, \mathrm{~d} 350, \mathrm{~d} 410, \mathrm{~d} 415, \mathrm{~d} 445, \mathrm{~d} 450, \mathrm{~d} 465, \mathrm{~d} 510$, \\
& $\mathrm{d} 520, \mathrm{~d} 530, \mathrm{~d} 540, \mathrm{~d} 550, \mathrm{~d} 560, \mathrm{~d} 760$ \\
\hline Environment & $\mathrm{e} 310, \mathrm{e} 320, \mathrm{e} 340, \mathrm{e} 355$ \\
\hline
\end{tabular}

The first working stage started by an Exploratory Factor Analysis (EFA), including the 31 codes listed in Table 1, in order to find the number of latent factors that explained the relational structure of the items, using IBM SPSS Statistics version 24.0.0 (IBM, 
Armonk, NY), as described in Marôco [19]. After that, the resulting factorial structure was processed by a Confirmatory Factor Analysis using the software AMOS (v.24, SPSS, an IBM company, Chicago, IL), in order to obtain the respective factorial validity of the resulting factorial structure, as suggested in Marôco [20]. The third stage encompassed a CFA with a second order factor, in order to infer each $f s w$ ICF codes, which can be used to compute the functional profiles scores, and compared them with those computed adopting an unitary weight for each item, as proposed by the authors in [10].

The final task comprised a short descriptive analysis, to describe the biological and sociodemographic variables of the sample data, using absolute and relative frequencies.

\section{Results}

\subsection{Exploratory Factor Analysis}

After checking some few deviations of normality assumption of the 31 items (codes ICF), based on the analysis of skewness (Sk) and kurtosis $(\mathrm{Ku})$, notably using thresholds of $|\mathrm{Sk}|<3$ and $|\mathrm{Ku}|<10$ (as suggested by Marôco in [19]), the EFA analysis was based on the Spearman's correlation matrix. Results can be shown in Table 2.

Results presented in Table 2 shows that the obtained factorial structure exhibit five latent factors (after iteratively removal of codes b280, b420, b440, b445, b525, and s810, which started with the initial number of eight latent factors), following the rule of "eigenvalue greater than 1". Almost $100 \%$ of the 25 factor loadings are equal or greater than 0.5 , while four latent factors presented mean values of the respective factor loadings equal or greater than 0.7 , expect for factor "F5" due to some lower factor loadings, but all greater than 05 . Regarding the communalities, almost all were large (only $20 \%$ present values less than 0.5 , but none of them are below than 0.3 , which can be a threshold considered appropriate for this type of construct). The total variance explained by the model is higher than $60 \%$ $(64.3 \%)$, with the "F1" latent factor explaining more than $50 \%$ of this variance. Finally, the recommendation to the EFA was considered as "Excellent", according to the Kaiser-MayerOlkin adequacy measure $(\mathrm{KMO}=0.909)$. Moreover, regarding some adjustment indexes to evaluate the quality of the model adjustment, like the goodness-of-fit and the adjusted goodness-of-fit indices, they present relative poor, $(\mathrm{GFI}=0.630$ and AGFI $=0.350)$, which may be related to the relative low facto loadings

o "F5", although a "very good" RMSR* of 0.05 was achieved

Regarding the contents of the ICF codes (items of EFA), we produced the following

thematic classification of the five Latent factors, based on [17, 18]: (i) "F1" = "Self-care in activities of daily living"; (ii) "F2" = "Self-care in fundamental human needs";(iii) "F3" = "Mental functions"; (iv) "F4" = "Communication"; (v) "F5" = "Support and relationships", with some similarity to the one proposed by Fonseca et al. [10]. 
Table 2. EFA results, leading to five retained latent factors, respective factor weights and communalities.

\begin{tabular}{|c|c|c|c|c|c|c|}
\hline \multirow[t]{2}{*}{ ICF codes (items) } & \multicolumn{5}{|c|}{ Latent factors ${ }^{\mathrm{a}}$} & \multirow[t]{2}{*}{ Communalities } \\
\hline & F1 & F2 & F3 & F4 & F5 & \\
\hline $\mathrm{d} 450$ & .807 & - & - & - & - & .716 \\
\hline d4410 & .804 & - & - & - & - & .747 \\
\hline $\mathrm{d} 465$ & .763 & - & - & - & - & .666 \\
\hline $\mathrm{d} 415$ & .761 & - & - & - & - & .646 \\
\hline d230 & .753 & - & - & - & - & .703 \\
\hline d510 & .651 & - & - & - & - & .720 \\
\hline $\mathrm{d} 520$ & .649 & - & - & - & - & .714 \\
\hline $\mathrm{d} 540$ & .568 & - & - & - & - & .711 \\
\hline Mean value & .720 & - & - & - & - & - \\
\hline d550 & - & .808 & - & - & - & .791 \\
\hline $\mathrm{d} 560$ & - & .781 & - & - & - & .772 \\
\hline $\mathrm{d} 530$ & - & .492 & - & - & - & .508 \\
\hline Mean value & - & .694 & - & - & - & - \\
\hline b114 & - & - & .816 & - & - & .792 \\
\hline b110 & - & - & .809 & - & - & .795 \\
\hline b140 & - & - & .795 & - & - & .761 \\
\hline b152 & - & - & .587 & - & - & .489 \\
\hline b144 & - & - & .570 & - & - & .523 \\
\hline b164 & - & - & .495 & - & - & 595 \\
\hline Mean value & - & - & .679 & - & - & - \\
\hline $\mathrm{d} 350$ & - & - & - & .799 & - & .821 \\
\hline $\mathrm{d} 330$ & - & - & - & .741 & - & .751 \\
\hline $\mathrm{d} 310$ & - & - & - & .662 & - & .713 \\
\hline Mean Value & - & - & - & .734 & - & - \\
\hline e310 & - & - & - & - & .718 & .548 \\
\hline $\mathrm{e} 320$ & - & - & - & - & .644 & .469 \\
\hline e355 & - & - & - & - & .533 & .336 \\
\hline $\mathrm{e} 340$ & - & - & - & - & .515 & .390 \\
\hline $\mathrm{d} 760$ & - & - & - & - & .504 & .403 \\
\hline Mean value & - & - & - & - & .583 & .643 \\
\hline Eigenvalues & 9.749 & 1.606 & 2.156 & 1.438 & 1.129 & - \\
\hline Variance explained & $39.0 \%$ & $6.4 \%$ & $8.6 \%$ & $5.8 \%$ & $4.5 \%$ & - \\
\hline Cronbach's alfa ${ }^{\mathrm{b}}$ & $\begin{array}{l}\alpha=0.924 \\
\text { (Very good) }\end{array}$ & $\begin{array}{l}\alpha=0.779 \\
\text { (Reasonable) }\end{array}$ & $\begin{array}{l}\alpha=0.848 \\
\text { (Good) }\end{array}$ & $\begin{array}{l}\alpha=0.853 \\
\text { (Good) }\end{array}$ & $\begin{array}{l}\alpha=0.580 \\
\text { (Almost } \\
\text { unallowable) }\end{array}$ & - \\
\hline
\end{tabular}

${ }^{\mathrm{a}}$ Extraction Method: Principal Component Analysis.

Rotation Method: Varimax with Kaiser Normalization;

Rotation converged in 7 iterations.

${ }^{\mathrm{b}}$ Qualitative classification adopted from [19]. 


\subsection{Confirmatory Factor Analysis}

The second stage of this researched consisted on a CFA, using the factorial structure obtained from EFA (see Table 2), as a testable model. The computation started based on a first order model as shown in Fig. 1. The names included in the symbols repre-senting the five latent factors are abbreviations of the thematic names that were given in the above section, notably: (i) "Self-care in activities of daily living" - "SC-ADL";(ii) "Mental Functions" - "MF"; (iii) "Self-care in fundamental human needs" - "SC-FHN"; (iv) "Communication" - "COM"; (v) "Support and relationships" - "SR". The goodness of fit of the adjusted model can be assessed by reading the respective adjust-ment indexes listed at the top of Fig. 1. All the thematic names given to each latent factor were done in respect to the contents of ICF codes description, the name of ICF groups of codes [17, 18], as well as including the recommendations described in [10].

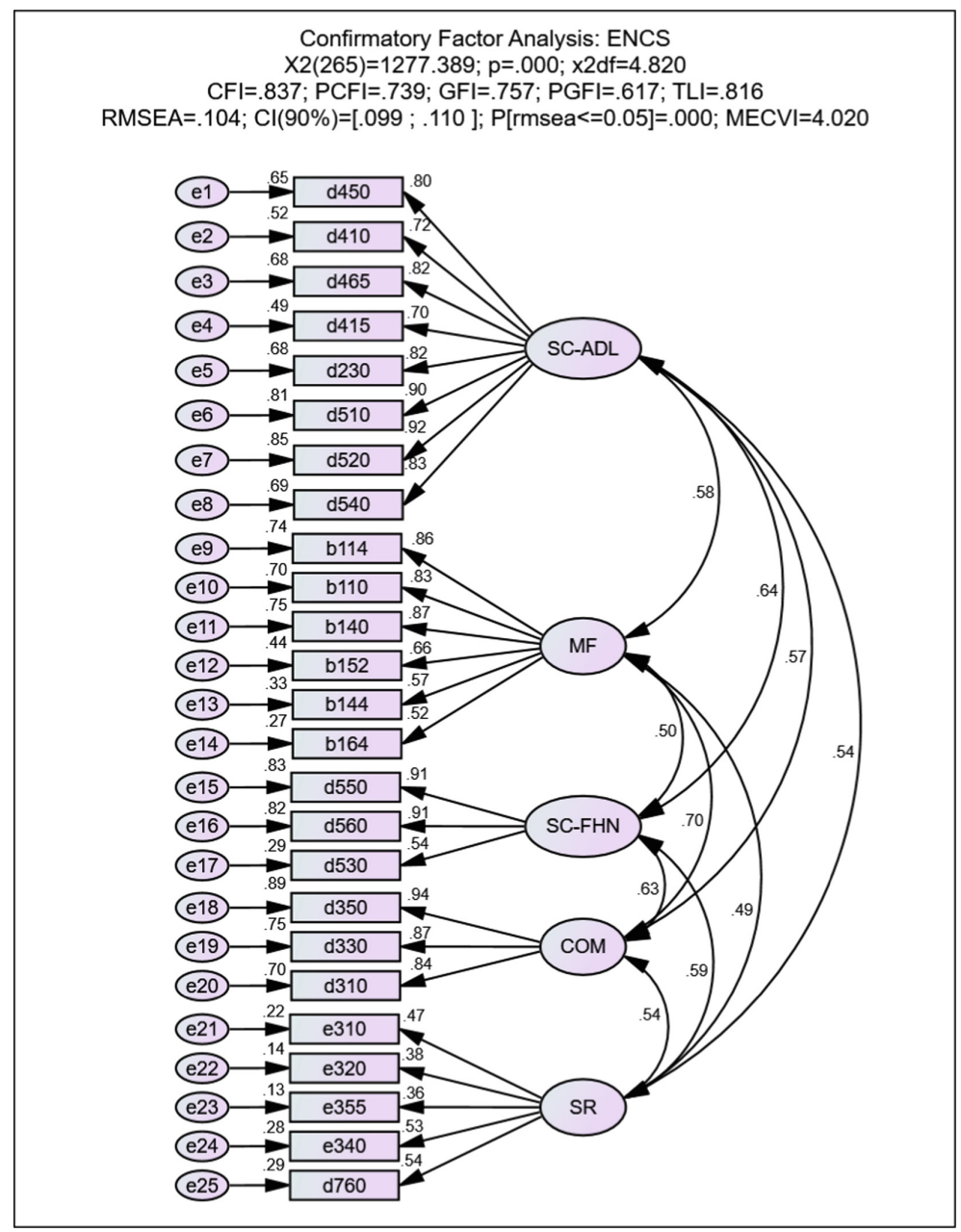

Fig. 1. Initial CFA model including the 25 items extracted from the EFA. 
As can be seen, the model fit is poor: (i) Chi-squared statistics divided by the degrees of freedom $\left(\chi^{2} / d f\right)$ is almost equal to 5; (ii) Comparative fit index (CFI) stays between [0.8; 0.9[; (iii) Goodness-of-fit index (GFI) is less than 0.8; (iv) Root Mean Square Error of Approximation (RMSEA) is greater than 0.1, among other issues (see Table 4.1 in [20] for the qualitative classification).

However, to achieve a better fit, the errors of observed variables (referred from "e1" until "e25"), were correlated, based on the modification indexes (MIs > 11) as suggested by Marôco in [20]. As can be seen, the Mean Expected Cross-Validation Index (MECVI) shown at the top of Fig. $2(M E C V I=2.897)$ is lower than the previous model $(M E C V I=$ 4.020), which allows inferring that model in Fig. 2 presents a better global fit when compared to the model shown in Fig. 1.

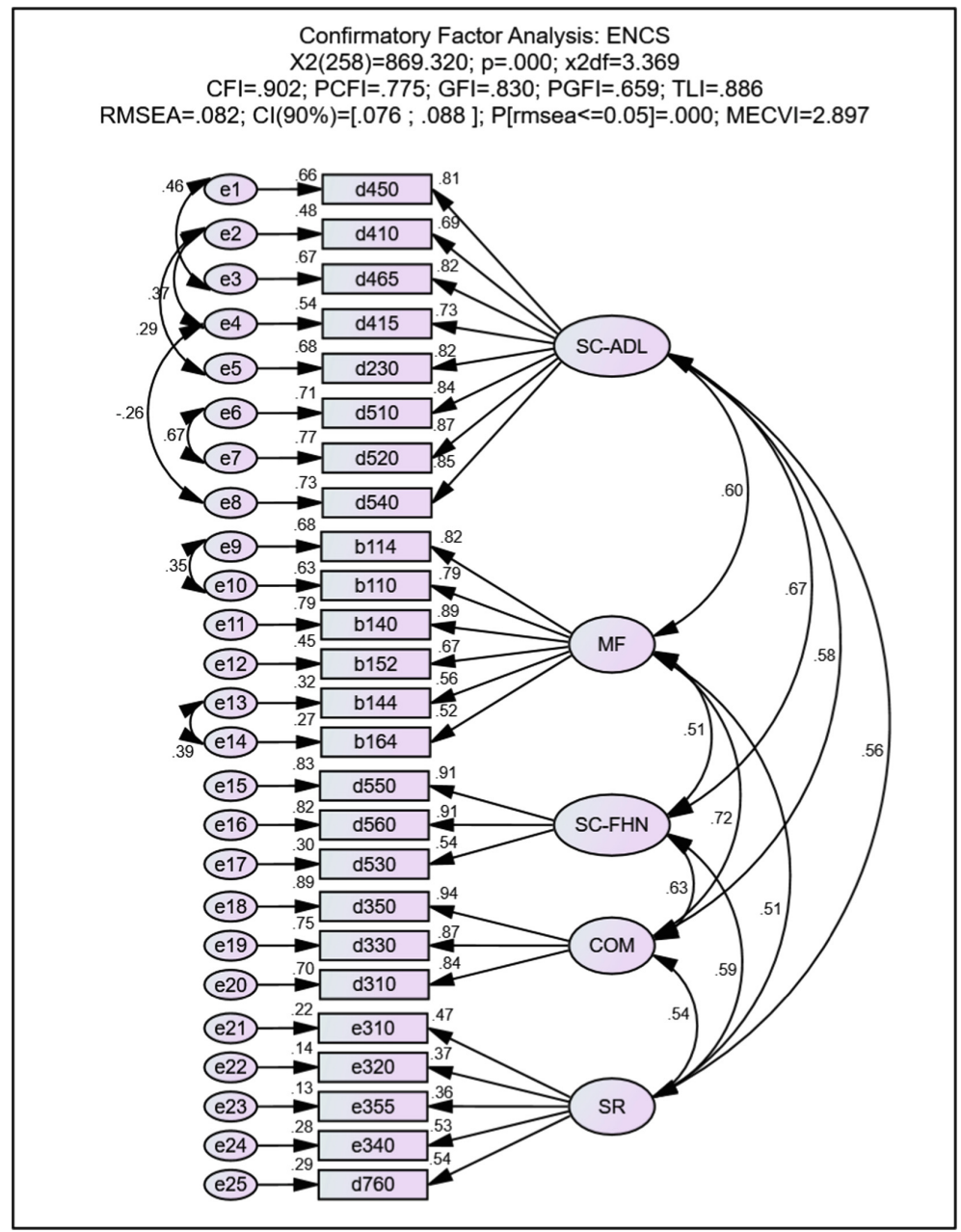

Fig. 2. Adjusted model based on the modification indexes (MI $>11$, this threshold suggested by Marôco in [20]) 
The quality of the adjusted model can be now classified as reasonable: (i) Chi-squared statistics divided by the degrees of freedom $\left(\chi^{2} / d f\right)$ is almost equal to 3; (ii) Comparative fit index (CFI) is "good", staying between [0.9; 0.95[; (iii) Goodness-of-fit index $(G F I)$ is "favorable", staying between [0.8; 0.9[; (iv) Root Mean Square Error of Approximation (RMSEA) is "acceptable", staying between [0.05; 0.1[; Tucker-Lewis Index (TLI) is "favorable", staying between [0.8; 0.9[, (see Table 4.1 in [20] for the qualitative classifications used here). Regarding the model adjustment based on the MI values, it is important to refer that the process must be grounded on some theoretical aspects of the model, and not only correlate those errors because the involved MI values are high. For example, we assume that some of the items present some similarity in their formulation, and their contents are some way related, as an example: "d410 Changing basic body position" (brushing teeth, shaving, grooming, etc.) and "d415 Maintaining a body position" (bathing, drying, washing hands, etc.). As can be seen, these both codes refer the same body positions, like Squatting, Kneeling, Sitting, Standing, Bending, which may confuse respondents. The items individual reliability was measured by the respective standardized factor loadings $(\lambda)$, with only two presenting values lower than 0.4 and a third almost equal to 0.5 , which allows us to assume a "Favorable" factorial validity of the construct. The construct reliability (internal consistency) was evaluated through the Cronbach's Alfa $\left(\alpha_{c}\right)$ and composite reliability (CR), whose values are listed in Table 3 and almost greater than 0.7, as recommended in Marôco [20]. However, according to Hair et al. [21], values less than 0.7 may be accepted in case of exploratory research, which is the case here, thus we also assume a "favorable" reliability of the construct. Finally, regarding the construct validity (CV), we started by assuming a factorial validity of the construct, since it was checked that the items effectively conceive the "big picture" that is actually being measured by the specific latent factors. In relation to the convergent validity of the construct, this characteristic was evaluated by the average variance extracted of the CFA model (AVE) [20]. The results in Table 3 shows that only "SR" factor present a "fair" convergent validity (AVE values must be greater than 0.5 , as suggested in Marôco [20]) which is due to the fact that this latent factor includes three standardized regression factor loadings lower than 0.5 (see Fig. 2). However, it is possible to foresee an almost overall "favorable" convergent validity of the adjusted CFA model.

Table 3. List of $\alpha_{c}$, CR and AVE index values.

\begin{tabular}{l|l|l|l}
\hline Latent factors & $\alpha_{c}$ & $\mathrm{CR}$ & $\mathrm{AVE}$ \\
\hline SC-ADL & 0.924 & 0.938 & 0.654 \\
\hline MF & 0.848 & 0.863 & 0.521 \\
\hline SC-FHN & 0.779 & 0.841 & 0.649 \\
\hline COM & 0.853 & 0.914 & 0.780 \\
\hline SR & 0.580 & 0.564 & 0.210 \\
\hline
\end{tabular}

As an alternative solution to some high correlations between latent factors shown in model of Fig. 2 (all with $p<0.001$ ), we suggest a hierarchical model positioning an 


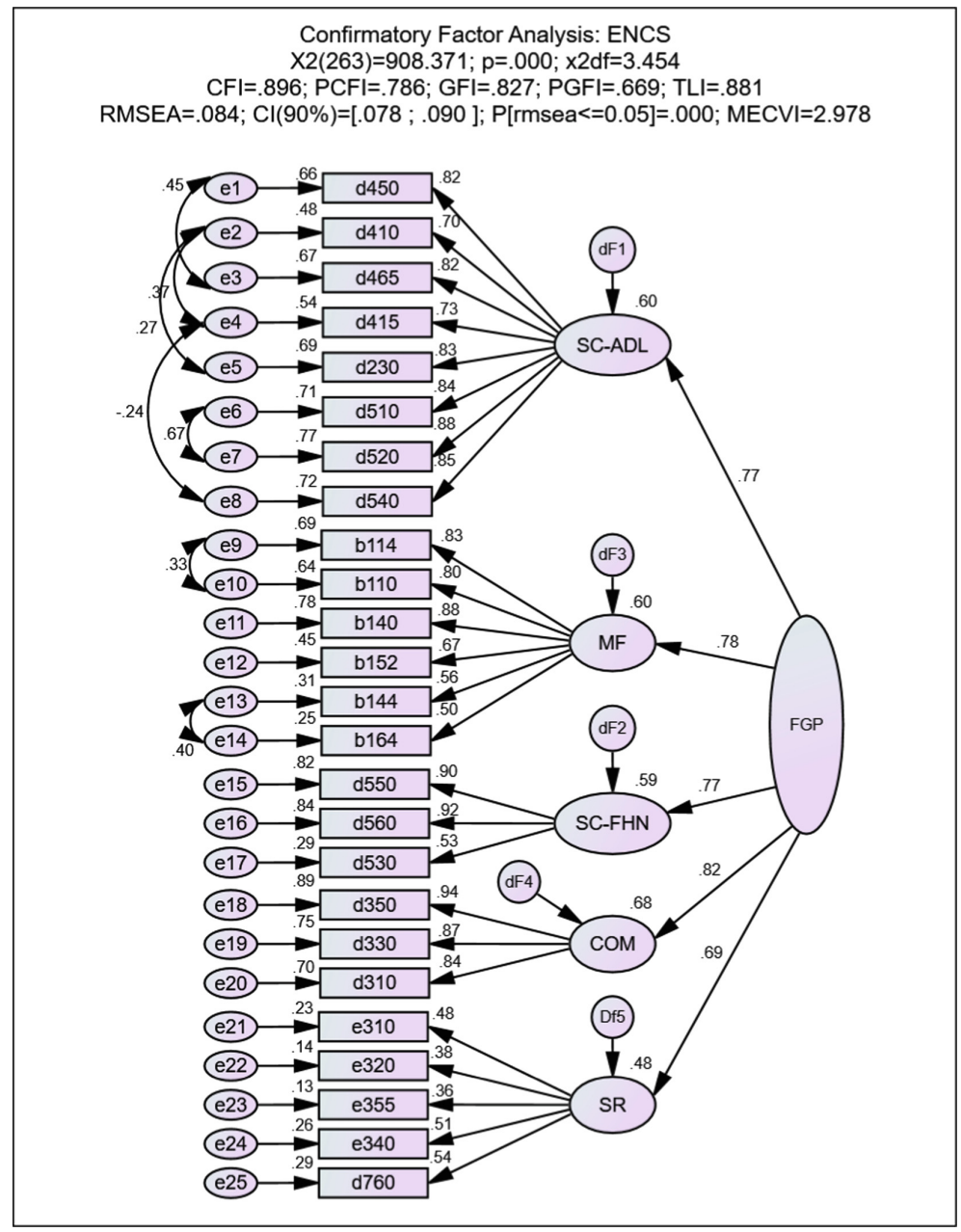

Fig. 3. Fitted second order factorial model adopting a FGP latent factor, after correlating the measurement errors of facets whose MI suggested their correlation (adopted MI > 11).

high order factor called Functioning General Profile - FGP (second order latent factor) as shown in Fig. 3, as recommended for this type of models in Marôco [20].

As can be seen by the values at the top of Fig. 3, this second order model shows a reasonable fit indexes (similar to the ones presented in top of Fig. 2), with the second factor order being the FGP measure, expressed through the various items (observed variables) and associated with each of the five latent factors. In respect to the correlations between FGP and the five latent factors, all were somehow high and all are statistical highly significant ( $p$ $<0.001$ ): (i) $\rho_{S C-A D L}=.77$; (ii) $\rho_{M F}=.78$; (iii) $\rho_{S C-F H N}=.77$; (iv) $\rho_{C O M}=.82$; (v) $\rho_{S R}=.69$. Regarding FC, $\alpha_{c}$ and AVE index values for FGP latent factor, respective very good values were obtained: $0.878,0.921$ and 0.591 , respectively. 
Based on the CFA results, a factor score weight $(f s w)$ is extracted for each item (ICF code), which allows computing the scores of those six latent factors (SC-ADL, SC-FHN, MF, COM, SR and FGP), for each citizen individually. According to the authors of the original ENCS [10], the score of each latent factor is computed as the average value of the items (ICF codes) that are included in the respective latent factor, thus using a $f s w$ value of " 1 " for each item. However, in this paper we propose the computation of individual's functional profile scores of each latent factor based on the $f_{s w}$ available for each item. Table 4 shows the adjusted $f s w$ and how to compute the new scores of each latent factor (profiles).

Table4.Proposed formulae used to compute the individual's functional profile scores based on the $f s w$ extracted from the CFA second order model shown in Fig. 3.

\begin{tabular}{|c|c|}
\hline $\begin{array}{l}\text { Latent } \\
\text { factor }\end{array}$ & Formulae $(f s w \times$ individual responses to the ICF codes $)$ \\
\hline SC-ADL & $\begin{array}{l}0.104 \times \mathrm{d} 450+0.001 \times \mathrm{d} 410+0.104 \times \mathrm{d} 465+0.156 \times \mathrm{d} 415+0.139 \times \mathrm{d} 230+ \\
0.066 \times \mathrm{d} 510+0.172 \times \mathrm{d} 520+0.258 \times \mathrm{d} 540\end{array}$ \\
\hline SC-FHN & $0.406 \times \mathrm{d} 550+0.557 \times \mathrm{d} 560+0.037 \times \mathrm{d} 530$ \\
\hline MF & $\begin{array}{l}0.241 \times \mathrm{b} 114+0.176 \times \mathrm{b} 110+0.416 \times \mathrm{b} 140+0.104 \times \mathrm{b} 152+0.041 \times \mathrm{b} 144+ \\
0.022 \times \mathrm{b} 164\end{array}$ \\
\hline $\mathrm{COM}$ & $0.556 \times \mathrm{d} 350+0.285 \times \mathrm{d} 330+0.159 \times \mathrm{d} 310$ \\
\hline SR & $0.159 \times \mathrm{e} 310+0.093 \times \mathrm{e} 320+0.125 \times \mathrm{e} 355+0.289 \times \mathrm{e} 340+0.334 \times \mathrm{d} 760$ \\
\hline FGP & $\begin{array}{l}0.016 \times \mathrm{d} 450+0.000 \times \mathrm{d} 410+0.016 \times \mathrm{d} 465+0.024 \times \mathrm{d} 415+0.022 \times \mathrm{d} 230+ \\
0.010 \times \mathrm{d} 510+0.027 \times \mathrm{d} 520+0.040 \times \mathrm{d} 540+0.113 \times \mathrm{d} 550+0.154 \times \mathrm{d} 560+ \\
0.010 \times \mathrm{d} 530+0.047 \times \mathrm{b} 114+0.034 \times \mathrm{b} 110+0.081 \times \mathrm{b} 140+0.020 \times \mathrm{b} 152+ \\
0.007 \times \mathrm{b} 144+0.004 \times \mathrm{b} 164+0.154 \times \mathrm{d} 350+0.079 \times \mathrm{d} 330+0.044 \times \mathrm{d} 310+ \\
0.016 \times \mathrm{e} 310+0.009 \times \mathrm{e} 320+0.012 \times \mathrm{e} 355+0.029 \times \mathrm{e} 340+0.033 \times \mathrm{d} 760\end{array}$ \\
\hline
\end{tabular}

Based on the results listed in Table 4, it was possible to compute the average functional profiles for the entire sample, whose results are provided um Fig. 4. The "Mean*" values represent the scores computed based on the formulation proposed in [10], while "MeanFSW" values symbolize those scores computed using the formulae listed in Table 4. The remaining values in Fig. 4 represent: (i) "MaxDiff", the maximum positive differences at individual level (adopting "Mean*"-"MeanFSW"); (ii) "MinDiff", the minimum negative difference for the same minus operation, also at individual level; (iii) "StdDiff", the standard deviation between all individual differences, notably "MaxDiff" and "MinDiff". All the items were in Likert scale (1-5) and scores (ranging from 0 to $100 \%$ ) were computed based on the following equation:

$$
\text { Functional score }=25 \times \text { itens response }-25 .
$$




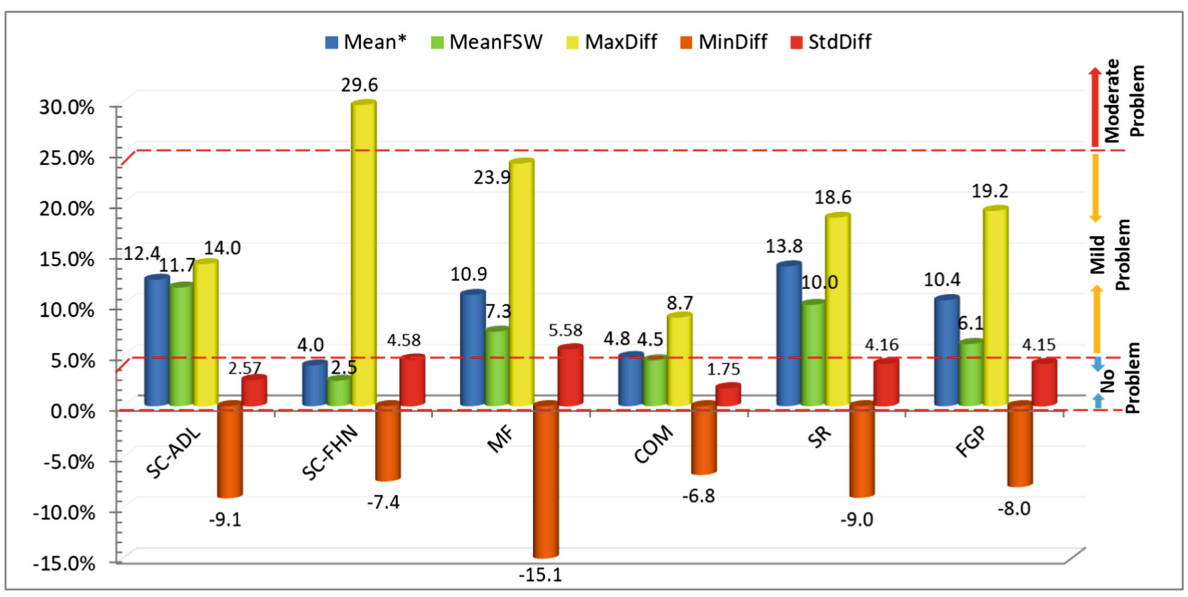

Fig. 4. Average functional profiles scores (for the entire sample for each of the six latent factors), computes using the $f s w$ extracted from the adjusted second order CFA model.

\subsection{Descriptive Statistics}

A short descriptive statistics of the sample data, processed under the scope of this research, is also provided in Table 5. The table lists the biological and sociodemographic characteristics of the 351 respondents residing in the region of BA.

Table 5. Biological and sociodemographic characteristics of the sample data.

\begin{tabular}{l|l|l}
\hline Biological and sociodemographic variables & $N$ & $\%$ \\
\hline Gender: & - & - \\
\hline Male & 163 & 46.4 \\
\hline Female & 188 & 53.6 \\
\hline Age group: & - & - \\
\hline $65-74$ & 132 & 37.6 \\
\hline $75-84$ & 135 & 38.5 \\
\hline 85 and higher & 84 & 23.9 \\
\hline Marital status: & - & - \\
\hline Single & 27 & 7.7 \\
\hline Married & 206 & 58.7 \\
\hline Divorced & 4 & 1.1 \\
\hline Widowed & 114 & 32.5 \\
\hline Educational level: & - & - \\
\hline Does not know how to read or write & 104 & 29.6 \\
\hline Knows how to read and write & 59 & 16.8 \\
\hline $1^{\text {st_4 }} 4^{\text {th }}$ grade & 165 & 47.0 \\
\hline More education & 23 & 6.6 \\
\hline
\end{tabular}




\section{Discussion}

Comparing the work developed in [10] with the one delineated in this paper, both show an "Excellent" recommendation regarding to the EFA, since the Kaiser-Mayer-Olkin adequacy measures are between the range] $0.9 ; 1.0$ ] [20]: 0.963 and 0.909 , respectively. Moreover, the work in [10] was able to extract four latent factors, while the one presented here is composed of five latent factors, whose the major difference is related to self-care: (i) one latent factor designated by "Self-Care" in [10]; (ii) two latent factors in the present proposal, namely "Self-care in activities of daily living" (composed by eight ICF codes) and "Self-care in fundamental human needs" (composed by three ICF codes). In relation to this topic, the present proposal may provide a little more detail regarding the citizens Self-care needs. Given the results of Bartlett's test of sphericity $(p<0.001)$, we rejected the null hypothesis and concluded that the variables of both constructs were significantly correlated. In addition, we established that the 25 indicators included in this component exhibit excellent internal consistency as also in [10].

Regarding the CFA results, adjustment indexes shows a very favorable adjusted CFA model, with the "SR" latent factor exhibiting the lowest reliability, motivated by three lower loadings, ranging from 0.5 and 0.3 , with this lower threshold $(0.3)$ being considered appropriate for this type of construct. Important issues regarding the validation of the construct based on CFA, reveal that the items achieved a very favorable individual reliability, and the construct reliability as also reached, although the "SR" latent factor was the one that presented a lower contribution for this validation issue, although values below 0.7 and greater than 0.5 may be accepted in case of exploratory research, like the one developed here, according to Hair et al. [21]. In relation to the construct validity, the factorial validity of the construct was also reached, since we checked that the items effectively conceive the "big picture" that is actually being measured by the specific latent factors. Regarding the convergent validity, only the "SR" latent factor presented a value less than 0.5 , which can be explained some of the lower loading factors of the respective items, whose mean values was $0.46((0.47+0.37+0.36+0.53+0.54) / 5)$. Finally the construct fails in terms of discriminant validity, because correlations between first-order factors were higher, associated to lower AVE values. In this point, a comparison to the work developed by César et al. it was not possible, because no CFA is available in [10].

Regarding the functional profiles scores calculated based on the $f s w$ extracted from CFA model shown in Fig. 3 and those computed according to the details provided in [10], the full scenario is depicted in Table 5. The analysis of the results shows that the global mean scores are almost similar for the "SC-ADL", "SC-FHN" and "COM" latent factors, and more pronounced for "MF", "SR" and "FGP", although always higher for "Mean*" than "MeanFSW". Almost all the global means reach a "Mild functional profile", except for "SC-FHN" (corresponding to "No Problem" functional profile). The most relevant aspect found is when making an individual analysis of the scores of each citizen, because there are differences in the results, which are higher positive differences for "SC-FHN", "MF", "SR" and "FGP", when compared to "SC-ADL" and "COM", and major negative differences in "MF". Those differences were the maximum found (either positive or negative), among all citizens composing the sample. We think that the differences between scores found must be carefully analyzed and it should be done by a 
group of health experts. Again, comparison at this level to the work developed by César et al. it was not possible, because no CFA is available in [10].

Finally, biological and sociodemographic characteristics of the sample show the presence of more females than males, the group of citizens presenting age a more advanced age as a relevant proportion in comparison to the other two. More than half of the citizens are married and almost half of the sample $(29.6 \%+16.8 \%=46.4 \%)$ never went to school, thus revealing an important aspect characterizing a lower literacy level of the citizens involved in this research.

\section{Conclusions}

As promoted by WHO, years lived in old age must not to be years of suffering and anguish, incapacities and dependencies, but rather years of meaning and quality of life, triggering processes that practice the available resources (individual and collective) in the redefinition of priorities, compensation of disabilities, adaptation to new situations, enabling the elderly to qualify, even when they have serious health problems enabling older people to remain a resource to their families, communities and economies [22].

We believe that the innovative work developed by Fonseca et al. [10, 16], and evaluated in this proposal on a different population sample, corroborate the recommendations in [10], i.e., the use of this type of Core Sets delineated the assess to the nursing care needs and/or to the outcomes of nursing interventions of citizens aged 65 years old or older, which will be also an ongoing process that will lead to the promotion of an Healthy Ageing and functional ability, which is stated as one of the frameworks promoted by WHO.

Acknowledgements. This work was supported by 4IE project (0045-4IE-4-P) funded by the Interreg V-A España-Portugal (POCTEP) 2014-2020 program.

Conflict of Interest. The authors declare that they have no conflicts of interest.

\section{References}

1. PORDATA: Ageing index [Internet]. PORDATA: The Database of Contemporary Portugal (2017). https://www.pordata.pt/en/Europe/Ageing+index-1609. Accessed 13 Oct 2019

2. United Nations: World Population Ageing 2019: Highlights. https://www.un.org/en/ development/desa/population/publications/pdf/ageing/WorldPopulationAgeing2019Highlights.pdf. Accessed 13 Oct 2019

3. INE: Life expectancy was 80.80 years at birth and 19.49 years at age $65-2016-2018$ [Demographic Data] (2019). Portuguese Life Tables. https://www.ine.pt/xportal/xmain?xpid= INE\&xpgid=ine_destaques\&DESTAQUESdest_boui=354096866\&DESTAQUESmodo= 2\&xlang=en. Updated 31 Mar 2019, Accessed 13 Oct 2019

4. PORDATA: Healthy life years at 65: by sex [Internet]. PORDATA: The Database of Contemporary Portugal (2017). (Male) https://www.pordata.pt/en/Europe/Healthy+life+years+at+ 65 +by+sex-1590-211621. (Female) https://www.pordata.pt/en/Europe/Healthy+life+years+ at +65+by+sex-1590-211622. Accessed 13 Oct 2019 
5. European Observatory on Health Systems and Policies: Health System Review - Portugal (Phase 1 Final Report) [Report]: World Health Organization (2018). https://www.sns.gov.pt/ wp-content/uploads/2018/04/PortugalReviewReport_Printers_03April2018-2.pdf. Accessed 13 Oct 2019

6. Gruneir, A., Silver, M.J., Rochon, P.A.: Review: emergency department use by older adults: a literature review on trends, appropriateness, and consequences of unmet health care needs. Med. Care Res. Rev. 68(2), 131-155 (2011). https://doi.org/10.1177/1077558710379422. https://journals.sagepub.com/doi/abs/10.1177/1077558710379422. Accessed 13 Oct 2019

7. Brandão, D., Ribeiro, Ó., Paúl, C.: Functional, sensorial, mobility and communication difficulties in the Portuguese oldest old (80+). Acta Médica Portuguesa - Revista da Ordem dos Médicos 30(6), 463-471 (2017). https://doi.org/10.20344/ amp.8060. https://www.actamedicaportuguesa.com/revista/index.php/amp/article/download/ 8060/5075. Accessed 13 Oct 2019

8. Hsieh, V.C.-R., Hsieh, M.-L., Chiang, J.-H., Chien, A., Hsieh, M.-S.: Emergency department visits and disease burden attributable to ambulatory care sensitive conditions in elderly adults. Sci. Rep. 9(3881) (2019). 9 p. https://doi.org/10.1038/s41598-019-40206-4. Accessed 13 Oct 2019

9. Petronilho, F.: Autocuidado - Conceito Central da Enfermagem. Formasau, Portugal (2012). $130 \mathrm{p}$.

10. Fonseca, C., Lopes, M., Mendes, D., Parreira, P., Mónico, L., Marques, C.: Psychometric properties of the elderly nursing core set. In: García-Alonso, J., Fonseca, C. (eds.) IWoG 2018. CCIS, vol. 1016, pp. 143-153. Springer, Cham (2019). https://doi.org/10.1007/978-3030-16028-9_13

11. Lesende, I., et al.: Functional decline and associated factors in patients with multimorbidity at 8 months of follow-up in primary care: the functionality in pluripathological patients (FUNCIPLUR) longitudinal descriptive study. BMJ Open 8, e022377 (2018). https://doi.org/10. 1136/bmjopen-2018-022377. 10 p. https://bmjopen.bmj.com/content/bmjopen/8/7/e022377. full.pdf. Accessed 13 Oct 2019

12. WHO: International Classification of Functioning, Disability and Health (ICF) [Web Page]. WHO Classifications. https://www.who.int/classifications/icf/en/. Accessed 14 Oct 2019

13. Chan, F., Gelman, J.S., Ditchman, N., Kim, J.-H., Chiu, C.-Y.: The World Health Organization ICF model as a conceptual framework of disability. In: Chan, F., Cardoso, E., Chronister, J. (eds.) Understanding Psychosocial Adjustment to Chronic Illness and Disability: A Handbook for Evidence-Based Practitioners in Rehabilitation, 1st edn, pp. 23-50. Springer, New York (2009)

14. Gonçalves, H., et al.: Population-based study in a rural area: methodology and challenges. Revista de Saúde Pública 52(Suppl 1) (2018). http://dx.doi.org/10.11606/s1518-8787. 2018052000270. 11s p. http://www.scielo.br/pdf/rsp/v52s1/0034-8910-rsp-52-s1-S1518-5287872018052000270.pdf. Accessed 14 Oct 2019

15. ULSBA: Unidade Local de Saúde do Baixo Alentejo (2016). http://www.ulsba.min-saude.pt/

16. Fonseca, C.: Modelo de autocuidado para pessoas com 65 e mais anos de idade, necessidades de cuidados de enfermagem. Ph.D. thesis, Universidade de Lisboa (2014). http://hdl.handle. net/10451/12196

17. WHO: How to use the ICF A Practical Manual for using the International Classification of Functioning, Disability and Health (ICF) (2013). https://www.who.int/classifications/icf/en/

18. WHO: ICF CHECKLIST Version 2.1a, Clinician Form for International Classification of Functioning, Disability and Health (2013). https://www.who.int/classifications/icf/en/

19. Marôco, J.: Análise Estatística com o SPSS Statistics, 6th edn., Report Number (2014). 990 p.

20. Marôco, J.: Análise de Equações Estruturais: Fundamentos teóricos, Software \& Aplicações, 2nd edn., Report Number (2014) 
21. Hair, J., Anderson, R., Tatham, R., Black, W.: Multivariate Data Analysis. Pearson Education Limited, New York (2014). 739 p.

22. WHO: Ageing and life-course - What is Healthy Ageing? (2019). https://www.who.int/ageing/ healthy-ageing/en/

"This is a post-peer-review, pre-copyedit version of an article published in Communications in Computer and Information Science book series (CCIS, volume 1185). The final authenticated version is available online at: https:// doi.org/10.1007/978-3-030-41494-8_31”. 